\title{
GAIA Level 1 Preeclampsia
}

National Cancer Institute

\section{Source}

National Cancer Institute. GAIA Level 1 Preeclampsia. NCI Thesaurus. Code C128003.

GAIA Level 1 Preeclampsia is defined by three criteria: first, the gestational age of the pregnancy must be greater than or equal to 20 weeks; second, a diagnosis of new onset maternal hypertension (systolic blood pressure greater than or equal to $140 \mathrm{mmHg}$ and/or diastolic blood pressure greater than or equal to $90 \mathrm{mmHg}$ ) that is sustained on two measurements over a minimum of one hour; third, a diagnosis of new onset proteinuria that is a level one diagnostic certainty (proteinuria diagnosed with greater than or equal to $300 \mathrm{mg}$ of protein during 24 hour urine collection OR greater than or equal to 0.3 for spot protein:creatinine ratio.) 